\title{
Heat-shock protein HSPA4 is required for progression of spermatogenesis
}

\author{
Torsten Held, Amal Z Barakat, Belal A Mohamed, Ilona Paprotta, Andreas Meinhardt , \\ Wolfgang Engel and Ibrahim M Adham \\ Institute of Human Genetics, University of Göttingen, D-37073 Göttingen, Germany and ${ }^{1}$ Department of Anatomy \\ and Cell Biology, University of Giessen, D-35378 Giessen, Germany
}

Correspondence should be addressed to I M Adham; Email: iadham@gwdg.de

T Held and A Z Barakat are contributed equally to this work and should be considered co-first authors

\begin{abstract}
Heat-shock protein 110 (HSP110) family members act as nucleotide exchange factors (NEF) of mammalian and yeast HSP70 chaperones during the ATP hydrolysis cycle. In this study, we describe the expression pattern of murine HSPA4, a member of the HSP110 family, during testis development and the consequence of HSPA4 deficiency on male fertility. HSPA4 is ubiquitously expressed in all the examined tissues. During prenatal and postnatal development of gonad, HSPA4 is expressed in both somatic and germ cells; however, expression was much higher in germ cells of prenatal gonads. Analyses of Hspa4-deficient mice revealed that all homozygous mice on the hybrid C57BL/6J $\times 129 /$ Sv genetic background were apparently healthy. Although HSPA4 is expressed as early as E13.5 in male gonad, a lack of histological differences between $\mathrm{Hspa}^{-/-}$and control littermates suggests that $\mathrm{Hspa} 4$ deficiency does not impair the gonocytes or their development to spermatogonia. Remarkably, an increased number of the Hspa4-deficient males displayed impaired fertility, whereas females were fertile. The total number of spermatozoa and their motility were drastically reduced in infertile $\boldsymbol{H s p a 4 - d e f i c i e n t}$ mice compared with wild-type littermates. The majority of pachytene spermatocytes in the juvenile $\mathrm{Hspa}^{-/-}$mice failed to complete the first meiotic prophase and became apoptotic. Furthermore, down-regulation of transcription levels of genes known to be expressed in spermatocytes at late stages of prophase I and post-meiotic spermatids leads to suggest that the development of most spermatogenic cells is arrested at late stages of meiotic prophase I. These results provide evidence that HSPA4 is required for normal spermatogenesis.

Reproduction (2011) 142 133-144
\end{abstract}

\section{Introduction}

Complexes containing heat-shock proteins (HSPs) represent the major components of molecular chaperones that facilitate the folding and assembly of newly synthesized proteins and the selection of unfolded proteins for degradation in different cellular compartments such as cytosol, endoplasmic reticulum, and mitochondria (Hartl 1996). Based on the molecular weight, HSPs are divided into structurally unrelated HSP110, HSP90, HSP70, HSP60, and HSP27 protein families (Vos et al. 2008).

The HSP110 gene family includes two genes in Saccharomyces cerevisiae known as SSE1 and SSE2 and four genes in the mammalian genome, namely HSPA4I/APG1, HSPA4/APG2, HSPH1/HSP105, and HYOU1/GRP175/ORP150. Except HYOU1, which is present in the endoplasmic reticulum, all other members of mammalian and yeast HSP110 are found in the cytosolic compartment (Vos et al. 2008). Primary structure of HSP110 proteins is highly related to HSP70 and consists of a nucleotide-binding domain (NBD) and a peptide-binding domain (PBD) that are connected by a flexible linker region (Mayer \& Bukau 2005, Liu \& Hendrickson 2007). However, biochemical analyses revealed that HSP110 members are co-chaperones of mammalian and yeast HSP70 chaperones and act as nucleotide exchange factors (NEF) during the ATP hydrolysis cycle (Steel et al. 2004, Dragovic et al. 2006, Raviol et al. 2006, Polier et al. 2008, Schuermann et al. 2008). Binding of newly synthesized polypeptides to HSP70 chaperone and subsequent release of folded proteins is regulated by a continuous cycle of ATP hydrolysis and exchange of ATP to ADP.

Beside HSP110 proteins, there are other unrelated nucleotide exchange factors of BAG and HSPBiP1 protein families. It is believed that the chaperones containing HSP70, HSP40, and HSP110 proteins represent the major protein folding machine of the eukaryotic cytosol (Polier et al. 2008).

Male germ cells undergo a dramatic developmental process, which is precisely controlled at the level of transcription and translation. After colonizing the 
primordial germ cells in mouse testis, gonocytes proliferate until day 15.5 and arrest in the G1 of cell cycle (Vergouwen et al. 1991, Nagano et al. 2000). Shortly after birth, gonocytes resume mitotic activity and develop into type A spermatogonia (Mclean et al. 2003). Primary spermatocytes undergo meiotic division to produce haploid round spermatids that are subsequently differentiated into mature sperm. Chaperone activities are required to mediate folding of de novo synthesized proteins and refolding of misfolded proteins during development of male germ cells (Eddy 1999). Mutation in the Hspa2 gene (Hsp70-2), which is highly expressed in pachytene spermatocytes, leads to arrest the spermatogenesis in meiotic prophase I and the majority of late pachytene spermatocytes are eliminated by apoptosis (Dix et al. 1997). Loss of DNAJA1, a co-chaperone of HSP70s in protein folding, results in severe defects of spermatogenesis (Terada et al. 2005).

To date, relatively little is known about the expression and the physiological function of HSPA4. In adult mouse, Hspa4 mRNA is detected in most tissues, with the highest expression in testis, ovary, and spleen (Kaneko et al. 1997). In vitro studies have shown that the expression of Hspa4 is not inducible by heat shock (Nonoguchi et al. 1999). Interestingly, expression of Hspa4 is up-regulated in some leukemia and solid tumors (Gotoh et al. 2004, Li et al. 2010).
To determine the expression pattern of HSPA4, we investigated the expression of HSPA4 in different tissues and during prenatal and postnatal testis development. To examine the function of HSPA4 in vivo, we generated Hspa4-deficient mice and subsequently determined the effect of HSPA4 deficiency on germ cell development.

\section{Results}

\section{HSPA4 is highly expressed in embryonic gonocytes and oogonia}

To investigate the expression pattern of HSPA4, northern blot analysis was performed with total RNA from different tissues of adult mice. The $358 \mathrm{bp}$ cDNA probe containing the coding sequence of the C-terminus recognized two Hspa4 transcripts of 4.8 and $3.2 \mathrm{~kb}$ in all studied tissues. Expression levels of the $3.2 \mathrm{~kb}$ transcript were relatively higher in testis (Fig. 1A). Analysis of Hspa4 cDNA sequences in database revealed that a cDNA sequence (GI 60360215; AK 220167) contains two predicted polyadenylation sites that are spanning $1.75 \mathrm{~kb}$ region. To confirm that both mRNA isoforms result from alternative splicing of the 3'-untranslated region, an RNA blot was hybridized with the $596 \mathrm{bp}$ cDNA probe containing the sequence between both polyA signals. This probe only detected the $4.8 \mathrm{~kb}$ transcript (Fig. 1B). To further confirm these
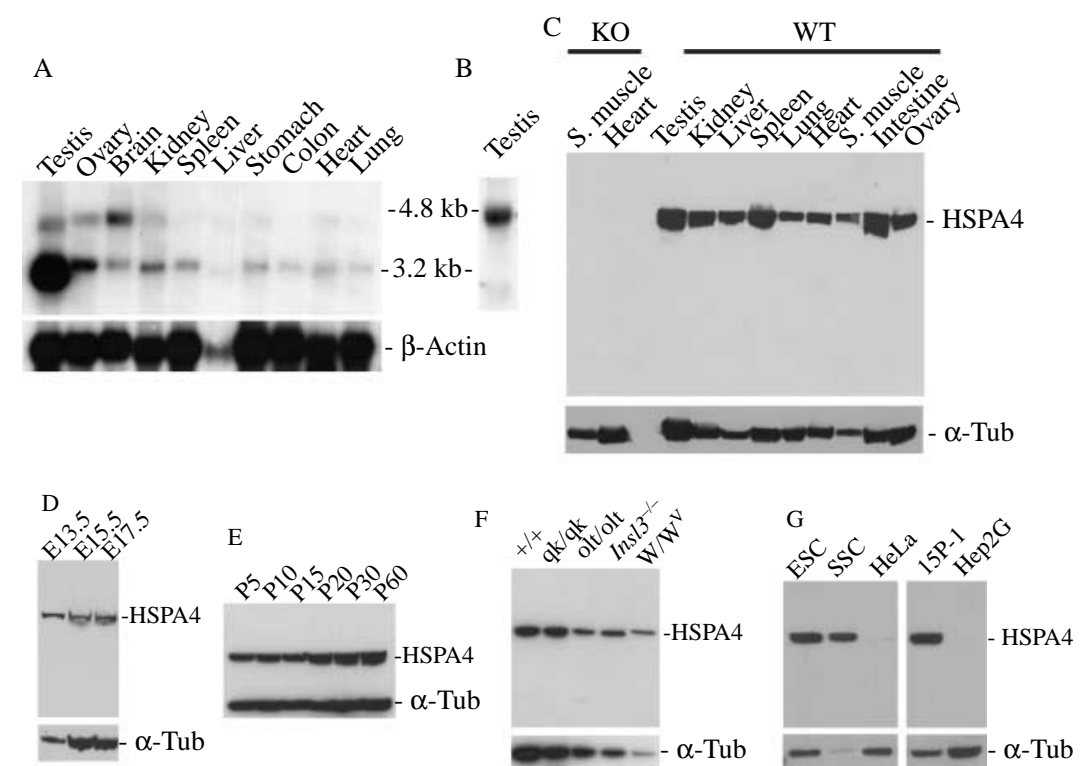

Figure 1 Expression pattern of HSPA4 in different tissues, fetal and postnatal testes, testes of different mutant mice, and different cell lines. (A) Northern blot with total RNA from different tissues of 3-month-old mice was hybridized with the 358 bp Hspa4 cDNA probe. The same blot was rehybridized with a $\beta$-actin cDNA probe. (B) RNA blot with RNA of adult testis was hybridized with the 596 bp Hspa4 cDNA probe. (C) Immunoblot of HSPA4 expression in cellular extracts from different tissues of 3-month-old wild-type (WT) and mutant mice (KO) revealed that anti-HSPA4 recognized a $96 \mathrm{kDa}$ protein in all wild-type tissue, but not in Hspa4-deficient tissues. (D and E) Expression of HSPA4 during prenatal (D) and postnatal testis development (E) was examined by immunoblotting using total lysates obtained from testes of E13.5, E15.5, and E17.5 embryos, and from P5, P10, P15, P20, P30, and P60 mice. The anti- $\alpha$-tubulin antibody ( $\alpha$-Tub) was used as a control. (F) Western blot with lysates obtained from testes of wild-type $(+/+)$ and different mutant mice was probed with anti-HSPA4 antibody. (G) Immunoblot of HSPA4 expression in cellular extracts from different cell lines. ESC, embryonic stem cells; SSC, spermatogonial stem cells; HeLa, HeLa cells; 15P-1, Sertoli cells, Hep2G, Hepatoma cells. 
results, western blot containing protein extracts of different wild-type and Hspa4-deficient tissues was probed with the anti-HSPA4 antibody. Immunoblot analysis revealed that the anti-HSPA4 recognized a $96 \mathrm{kDa}$ protein in all wild-type tissues, but not in Hspa4deficient tissues (Fig. 1C). To evaluate the expression pattern of HSPA4 during testis development, immunoblot analysis was performed with testis extracts obtained from mice at the different stages of prenatal and postnatal development. HSPA4 was detected throughout the prenatal and postnatal development of testis as shown in Fig. 1D and E. Expression levels of the HSPA4 are markedly increased in testis after postnatal day 20 suggesting an increased expression of the HSPA4 in haploid spermatids. We also examined the expression of HSPA4 in testes of mouse mutants. HSPA4 was present in testes of $W / W^{N}$ mutant mice that lack most germ cells as well as in testes of $q \mathrm{k} / q \mathrm{k}$, olt/olt, and Ins/3 ${ }^{-1-}$ mutant mice, in which spermatogenesis is arrested at different stages (Fig. 1F; Lyon \& Searle 1989, Chubb 1992, Zimmermann et al. 1999). Further immunoblot analysis was performed with protein extracts isolating from embryonic stem cells, spermatogonial stem cells (Guan et al. 2006), Sertoli cell line 15P-1 (Rassoulzadegan et al. 1993), HeLa, and hepatoma Hep2G cell line. HSPA4 was expressed in embryonic, spermatogonial stem, and
Sertoli cell lines, whereas its expression levels were lower in both HeLa and Hep2G (Fig. 1G). These results suggest that HSPA4 is expressed in somatic and germ cells of testis. To determine the cellular localization of HSPA4, immunocytochemical analysis was performed on sections of fetal and newborn testis and ovary after embryonic day 13.5. We observed that HSPA4 is highly enriched in male gonocytes of E13.5, whereas lower levels of HSPA4-immunostaining were seen in somatic cells (Fig. 2A). Expression of HSPA4 remains at high levels in gonocytes throughout fetal stages (Fig. 2B and C). After migration of gonocytes from central to peripheral layer of seminiferous tubules during neonatal development and their start to differentiate to differentiated spermatogonia in 5-day-old testis, HSPA4 still expressed but at lower level than in fetal gonocytes (Fig. 2D). In adult testis, the expression of HSPA4 is slightly increased in post-meiotic germ cells (Fig. 2E). The HSPA4-specific immunostaining was confirmed by the absence of HSPA4-immunostaining in adult Hspa4deficient testis (Fig. 2F). Immunofluorescence with antibodies directed against undifferentiated spermatogonia marker PLZF revealed that HSPA4 and PLZF are expressed in the same population of spermatogonia (Fig. 2G-I). When the preleptotene spermatocytes enter meiosis in 10-day-old testis, differentiated
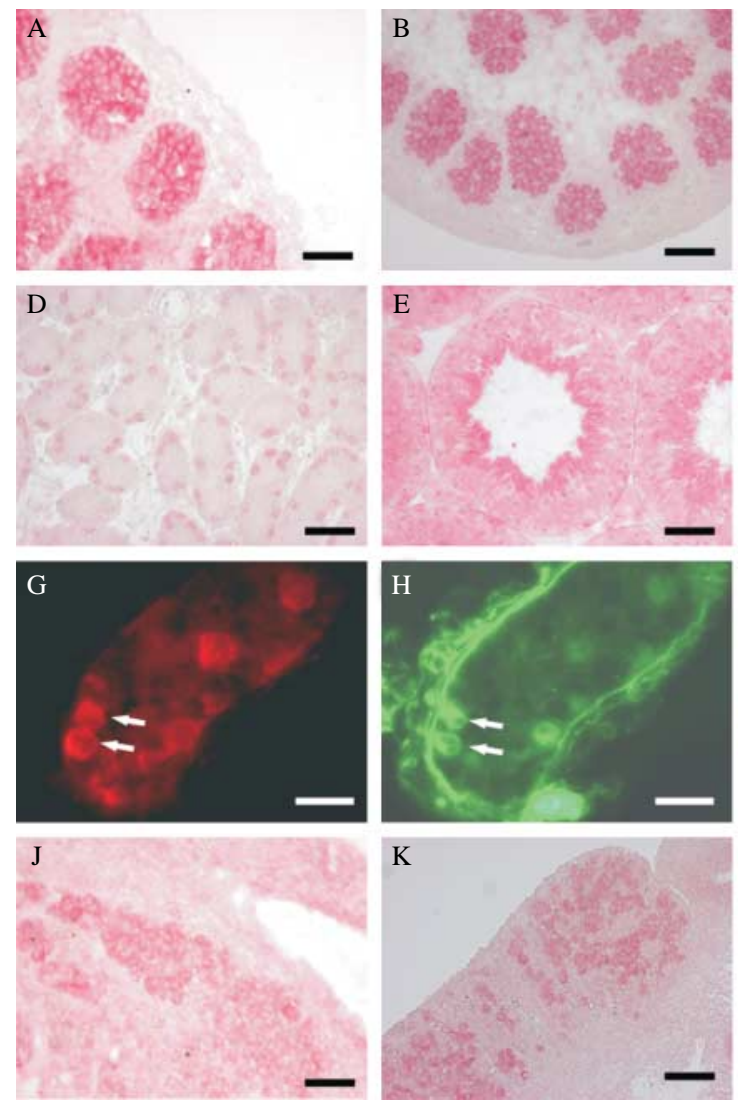
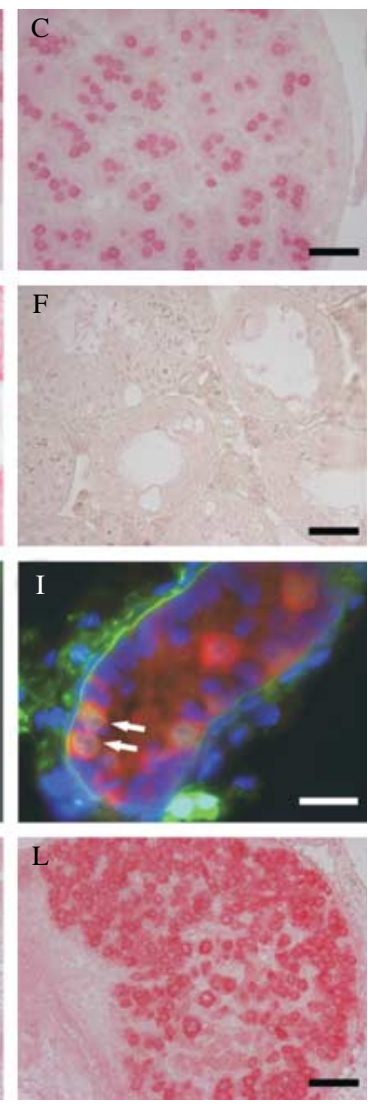

Figure 2 Cellular localization of HSPA4 during testis and ovary development. (A-F) Immunohistochemistry of paraffin sections with anti-HSPA4 shows an abundance of HSPA4 in the gonocytes of wild-type testes at E13.5 (A), E15.5 (B), E18.5 (C), and in spermatogonia at P5 (D). In 3-monthold wild-type testis, expression of the HSPA4 is slightly increased in post-meiotic germ cells (E). A negative control of immunohistochemistry is the absence of HSPA4-specific immunostaining in adult Hspa4-deficient testis (F). (G-I) Expression of the HSPA4 in undifferentiated spermatogonia of wild-type mice is confirmed by immunofluorescence of testis at P5 with anti-HSPA4 (G) and antiPLZF (H). HSPA4 and PLZF are expressed in the same population of spermatogonia (arrows). HSPA4 (red fluorescence) and PLZF (green fluorescence) are shown separately $(\mathrm{G}$ and $\mathrm{H})$ and merged (I). DAPI (blue fluorescence) was used for nuclear staining (I). (J-L) Immunohistochemistry with HSPA4 antibody was performed on ovary sections of E13.5 (J), E15.5 (K), and E18.5 (L). Scale bar A-F and J-L $=50 \mu \mathrm{m} ; \mathrm{G}-\mathrm{I}=20 \mu \mathrm{m}$. 
spermatogonia, leptotene, and zygotene spermatocytes are expressed HSPA4 at very low levels (data not shown). In prenatal ovary, oogonia of E13.5 show weak staining (Fig. 2J), whereas HSPA4 is highly expressed in oogonia of E15.5 and E18.5 (Fig. 2K and L). The high enrichment of HSPA4 in gonocytes and oogonia throughout their embryonic development suggests that the absence of HSPA4 protein might directly affect the development of germ cells in both male and female embryos.

\section{Hspa4 deficiency results in impaired male fertility}

To investigate the function of HSPA4, we inactivated the Hspa4 in mouse ESC. Hspa4-targeting vector was designed to replace a $3.0 \mathrm{~kb}$ genomic fragment containing exon 1 by neomycin resistance gene (Fig. 3A). Recombinant Hspa4 ${ }^{+/-}$ESCs were analyzed by Southern blot hybridization (Fig. 3B) and then used to generate chimeric mice. Chimeric mice were intercrossed with C57BL/6J females to establish the Hspa4 mutant allele on a C57BL/6J $\times 129 /$ Sv hybrid genetic background. Interbreeding of heterozygous mice yielded a normal Mendelian ratio of $\mathrm{Hspa}^{+/ /}, \mathrm{Hspa}^{+/-}$, and $\mathrm{Hspa}^{-1-}$ offspring. These results indicate that there is no lethality caused by the Hspa4 mutation. Male and female Hspa4-deficient mice developed into apparently normal adults. In Hspa4-null allele, exon 1 containing the translation initiation codon ATG is deleted.
Therefore, we expected that the targeted Hspa4 allele would be transcribed into an untranslated $\mathrm{Hspa} 4$ mRNA. The inactivation of Hspa4 was confirmed by RT-PCR and northern and western blot analyses. The 596 bp cDNA probe recognized a weak band in RNA from $\mathrm{Hspa}^{-/-}$ testis (Fig. 3C). RT-PCR with primers containing sequences of exons 1 and 3 was not able to amplify the Hspa4 cDNA fragment from testicular RNAs of Hspa4-deficient mice (Fig. 3D). At protein level, the HSPA4 antibody recognized the expected $96 \mathrm{kDa}$ HSPA4 protein in testes of wild-type and heterozygous animals, whereas the corresponding protein band was not detected in testes of Hspa4-deficient mice (Fig. 3E). These results confirm that the targeted disruption of Hspa4 generated a null mutation.

To study the consequence of Hspa4 mutation on female and male fertility, we intercrossed 13 males and seven females from $\mathrm{F} 2$ generation with wild-type mice of strain CD1 over a period of 3 months. All mating of Hspa4-deficient females were reproductive, and the average litter size $(9.2 \pm 2.4, n=18)$ was not significantly different compared to breeding with wild-type females $(9.6 \pm 1.6, n=15)$. Breeding of male mutants revealed that fertility was heterogeneous among males. Of the 13 males, eight did not produce a single litter, whereas the remaining five produce litter size $(11.1 \pm 3.4$, $n=16)$ similar to those of their wild-type littermates $(14.6 \pm 1.2, n=15)$.

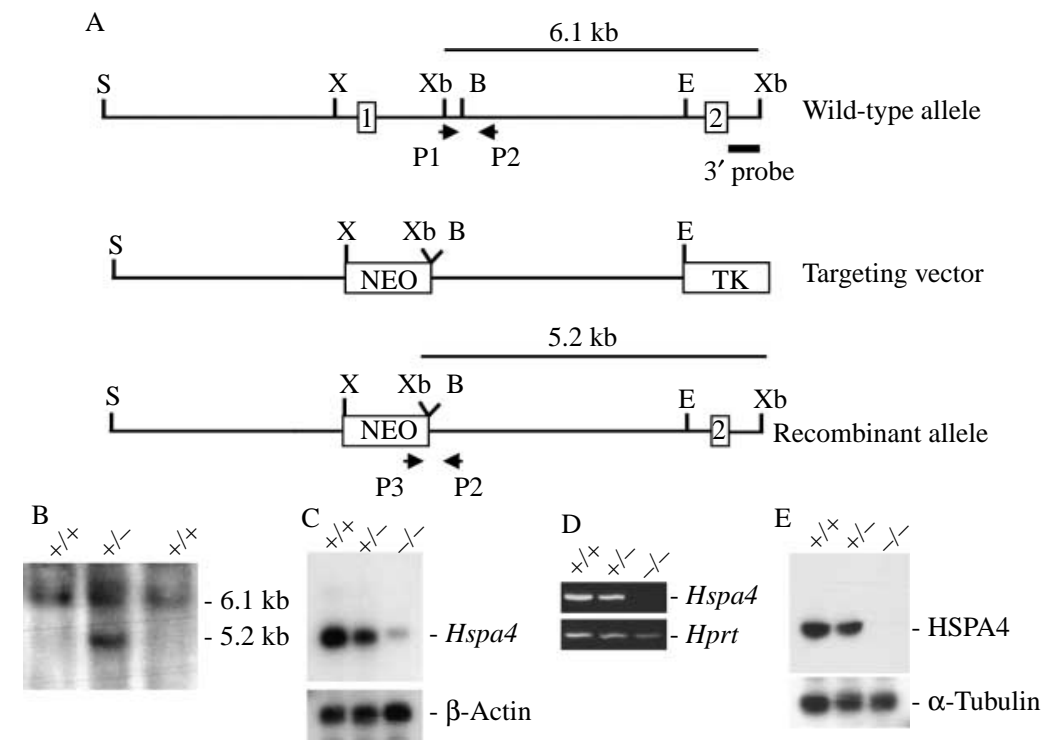

Figure 3 Targeted disruption of the Hspa4 gene. (A) Schematic representation of wild-type, targeted vector and recombinant allele. Exons are represented as numbered boxes. A $3.0 \mathrm{~kb}$ genomic fragment containing exon 1 was replaced by pgk-neo selection cassette (NEO). TK box represents thymidine kinase. The 3' external probe used and the predicted length of Xbal restriction fragments in Southern blot analysis are shown. The primers P1, P2, and P3 used to amplify the wild-type and mutant alleles by PCR are also indicated. Restriction sites relevant for generation of knockout vector and for screening strategies are Spel (S), Xhol (X), Xbal (Xb), BamHI (B) and EcoRI (E). (B) Southern blot analysis of recombinant ES cell (ESC) clones. Genomic DNA from ESC clones was digested with Xbal and probed with the 3'-probe shown in panel A. (C) Northern blot with testicular RNA of $\mathrm{Hspa}^{+/+}, \mathrm{Hspa}^{+/+}$, and Hspa4${ }^{-/-}$mice was hybridized with the $596 \mathrm{bp} \mathrm{Hspa4}$ and $\beta$-actin cDNA probes. (D) RT-PCR analysis using testicular RNA and primers located in exons 1 and 3 of $\mathrm{Hspa} 4$ confirmed the absence of exon 1 in $H_{s p a} 4$ targeted transcripts. Amplification of $H$ prt cDNA in assays with RNA of three genotypes was used as a control. (E) Western blot with whole protein extracts from testes of $H_{s p a 4}{ }^{+/+}, H_{s p a} 4^{+/-}$, and $\mathrm{Hspa}^{-1-}$ mice was probed with HSPA4 and $\alpha$-tubulin antibodies. 
To verify whether the Hspa4 deficiency results in disruption of spermatogenesis and/or sperm motility, we analyzed the number and the motility of spermatozoa collected from the cauda epididymides of 5-month-old wild-type, fertile, and infertile $\mathrm{Hspa}^{-1-}$ males. A significant reduction in the mean number of spermatozoa was found in $\mathrm{Hspa}^{-/-}$males. Analysis of sperm motility and progressive movement showed significant differences only between spermatozoa of wild-type and infertile $\mathrm{Hspa}^{-/-}$mice (Table 1).

\section{Spermatogenesis is arrested at meiotic prophase stage}

Testis weights of 5-month-old infertile Hspa4-null mice $(51.1 \pm 12.1 \mathrm{mg}, n=5)$ were significantly reduced than those of control males (125.4 $\pm 4.2 \mathrm{mg}, n=5$; Fig. 4A). To elucidate the cause of the reduction in number of spermatozoa, we analyzed cross sections of testes from 5-month-old wild-type and Hspa4-deficient mice. Testes of infertile mutant mice exhibited a diverse range of defects, varying in severity among males. Most seminiferous tubules were markedly smaller than those of wild-type controls (Fig. 4B and C). Tubules of testes from infertile mice contained Sertoli and early stages of spermatogenic cells; however, many pachytene spermatocytes have degenerated nuclei, and round and elongated spermatids were absent in most seminiferous tubules (Fig. 4D and E). Many tubules were vacuolated due to spermatocytes loss. Multinucleated spermatids, which may arise by widening of the intercellular bridges after meiotic division (Dym \& Fawcett 1971), were frequently observed (Fig. 4B and C). Consequently, the mutant epididymides contained a few number of sperm and immature germ cells with compact chromatin were present (Fig. 4F and G).

To identify the spermatogenic stage, at which spermatogenesis is affected by Hspa4 deficiency, testicular sections from different postnatal days were histologically and immunohistologically analyzed. No apparent differences were observed in the histological structure of seminiferous tubules between mutant and wild-type mice at postnatal days 5 and 10 (data not shown). Using the HSPH1 antibody to label gonocytes, the $\mathrm{Hspa}^{-/-}$and $\mathrm{Hspa}^{+/+}$tubules were observed to

Table 1 Sperm analysis of $\mathrm{Hspa}^{+/+}$and $\mathrm{Hspa}^{-/-}$mice.

\begin{tabular}{lccc}
\hline $\begin{array}{l}\text { Genotype } \\
\text { of mice }\end{array}$ & $\begin{array}{c}\text { No. of sperm in cauda } \\
\text { epididymis }\left(10^{7}\right)\end{array}$ & $\begin{array}{c}\text { Sperm } \\
\text { motility (\%) }\end{array}$ & $\begin{array}{c}\text { Progressive } \\
\text { motility }(\%)\end{array}$ \\
\hline $\begin{array}{l}H s p a 4^{+/+} \\
\text {Hspa4 }\end{array}$ & $2.0 \pm 0.1(5)$ & $63.2 \pm 4.4(5)$ & $42.1 \pm 5.3(5)$ \\
Fertile & $1.1 \pm 0.4^{*}(4)$ & $57.0 \pm 6.5(4)$ & $33.5 \pm 9(4)$ \\
Infertile & $0.2 \pm 0.3^{*}(5)$ & $18.3 \pm 11.4^{*}(4)$ & $9.8 \pm 5.9^{*}(4)$ \\
\hline
\end{tabular}

Data for sperm analysis represent the mean \pm s.D. for the numbers of individual measurements indicated in parentheses. *Value in $\mathrm{H}_{s p a 4^{-/-}}$mice is significantly different from that in $\mathrm{Hspa}^{+/+}$mice $(P<0.01$ by Student's $t$-test). contain equivalent numbers of gonocytes, suggesting that the Hspa4 deficiency does not impair gonocytes or development of gonocytes to spermatogonia (Supplementary Figure 1, see section on supplementary data given at the end of this article). At postnatal day 10, the first spermatocytes are formed. The number of germ cells stained with anti-GCNA1, a marker of pre-meiotic and meiotic germ cells, in mutant and wild-type tubules, was not significantly different at postnatal day 10, suggesting that mitotic division in mutant testes is not affected (Supplementary Figure 1). However, a few of the seminiferous tubules of $\mathrm{Hspa}^{-/-}$testes contained meiotic germ cells (pachytene spermatocytes) at postnatal day 15 (Fig. 5A and B). By immunohistological staining with anti-HSPA4L, which is highly expressed in germ cells from pachytene spermatocytes (Held et al. 2006), a reduction was observed in the mean number of HSPA4L-immunopositive cells per tubule in $\mathrm{Hspa}^{-1-}$ compared with wild-type testes (Supplementary Figure 1). At P20, spermatogenesis has reached the stage of round spermatids in majority of wild-type tubules. In contrast, mutant tubules were almost completely devoid of round spermatids and contained much fewer number of pachytene spermatocytes (Fig. 5C and D). At day 25, when tubules of wild-type littermates showed elongated spermatids, Hspa $4^{-1-}$ testes showed a severe depletion of germ cells. In Hspa4-deficient testes, very few tubules contained round spermatids as the most advanced germ cells ( $\mathrm{Fig}$. 5E and F). To examine whether disrupted spermatogenesis is due to the impairment of chromosomal pairing, we analyzed the formation of the synaptonemal complex in the mutant germ cells. No abnormalities in the chromosome pairing were detected as judged by the proper accumulation of SCPY3 on the synapsed chromosomes during pachytene stage (Supplementary Figure 1). These results suggest that the Hspa4 deficiency resulted in either developmental delay or partial arrest of the first wave of spermatogenesis.

To investigate whether the observed loss of germ cells is a result of enhanced apoptosis in Hspa4-null mice, TUNEL assay was performed on testis section of 10-, 15-, 20-, 25-, and 150-day-old mice. In 5-month-old testes, there were significantly more TUNEL-positive cells in seminiferous tubules of infertile $\mathrm{Hspa}_{\text {sp-null mice than in }}$ those of wild-type littermates (Fig. 6G and H). During postnatal development of testis, there were no significant differences in the number of TUNEL-positive cells between $\mathrm{Hspa}^{+/+}$and Hspa4 ${ }^{-/-}$testes at P10 (data not shown). A significant increase of TUNEL-positive spermatocytes was found in Hspa4-null mice at P15, P20, and P25 (Fig. 6A-F and I). These results indicate that germ cells at meiotic stages appear to be the most affected cells in Hspa4-deficient testes.

We then analyzed the expression of different meiotic and post-meiotic marker genes in testes of wild-type, fertile, and infertile mutant mice (Fig. 7A and B). 
A

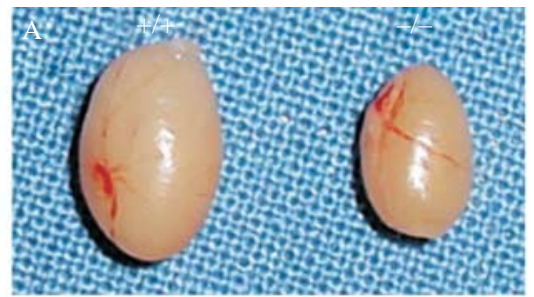

$+/+$
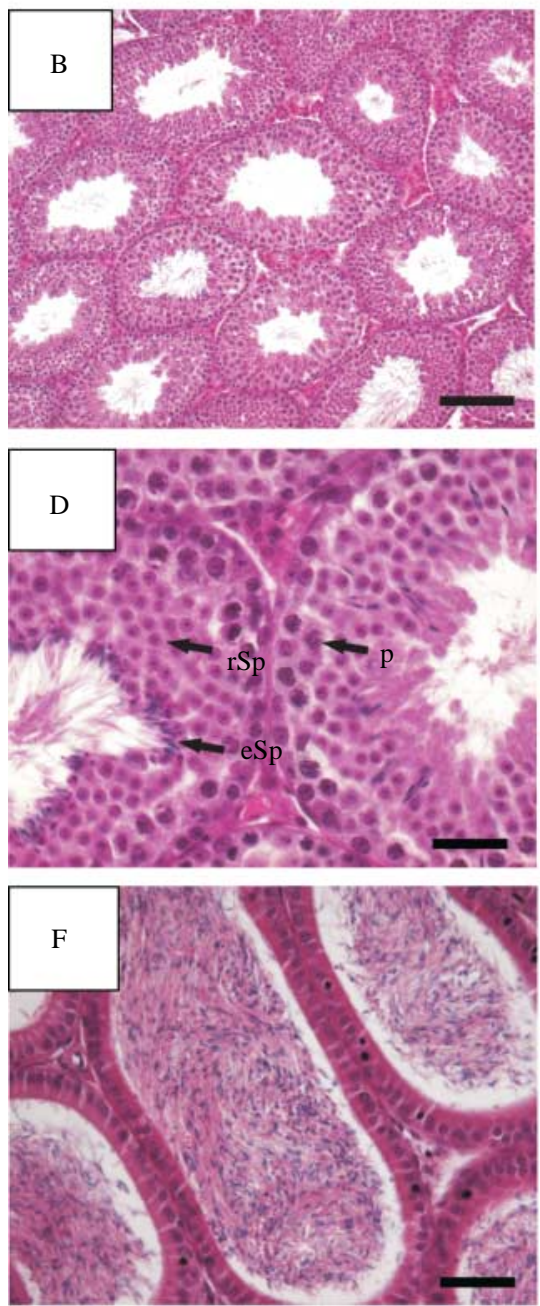
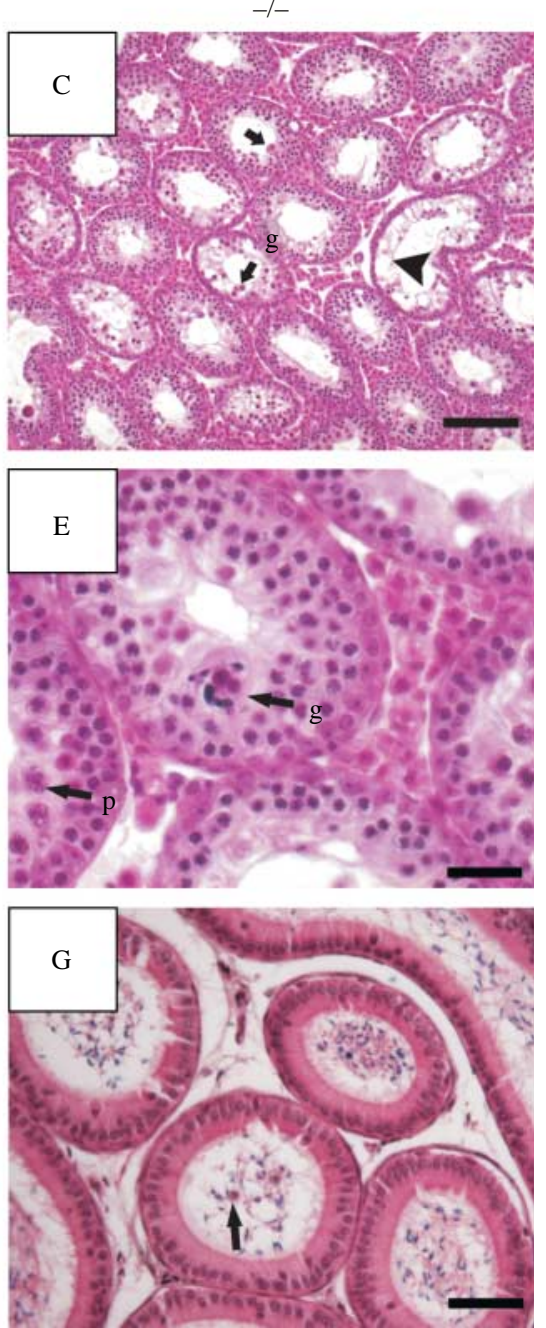

Figure 4 Testes and spermatogenesis of $\mathrm{Hspa}^{+/+}$ and infertile $\mathrm{Hspa}^{-/-}$mice. (A) Infertile $\mathrm{Hspa}^{-/-}$ mice showed reduced testis size compared with $\mathrm{Hspa}^{+/+}$mice. (B-E) Histological sections from testes of 5-month-old wild-type $(+/+)$ and $\mathrm{Hspa}^{-/-}$mice $(-/-)$were stained with hematoxylin and eosin (H\&E). A strongly reduced number of pachytene spermatocytes and round and elongated spermatids are found in most seminiferous tubules of mutant mice (C and E) compared with wild-type mice (B and D). Furthermore, degenerated germ cells and vacuoles (arrowhead) and presence of multinucleated giant cells (g) are frequently found in testes of infertile $\mathrm{Hspa}^{-/-}$mice. P, pachytene spermatocytes; rSp, round spermatids; eSp, elongated spermatids. ( $F$ and $G$ ) H\&E-stained sections of epididymides of 5-month-old mice. Hspa4-deficient epididymides contain a few number of sperm, and immature germ cells with compact chromatin were present (arrow). Scale bar $(B$ and $C)=100 \mu \mathrm{m} ;(D-G)=50 \mu \mathrm{m}$.
Expression of Sycp3 gene encoding synaptonemal complex protein-3 is restricted to leptotene and zygotene spermatocytes (Lammers et al. 1994). Northern blot analysis revealed that the expression levels of Sycp3 in testes of fertile and infertile $\mathrm{Hspa}^{-1-}$ mice are similar to those in wild-type testes. In contrast, expression of testis-specific genes encoding the phosphoglycerate kinase-2 (Pgk2) and acrosin (Acr), which were reported to be expressed in pachytene spermatocytes (Goto et al. 1990, Kashiwabara et al. 1990, Kremling et al. 1991), was markedly reduced in testes of infertile Hspa4-null mice. Similar results were also obtained for transcript levels of post-meiotic genes Hsc70t ( $\mathrm{Hsp} 70$ homolog gene) and transition nuclear protein 2 (Tnp2; Kleene \& Flynn 1987, Tsunekawa et al. 1999). These results confirm that the disruption of spermatogenesis in Hspa4-deficient mice occurred late in meiotic prophase I.

The mild phenotype in spermatogenesis of Hspa4-null mice may be due to overexpression of other members of HSP110 family. Therefore, we analyzed the expression of HSPA4L and HSPH1 in testes of fertile $\mathrm{Hspa}^{-/-}$ mice. Western blot analysis did not reveal a marked increase in the expression of HSPA4L and HSPH1 in testes of Hspa4-null mice (Fig. 7C). 

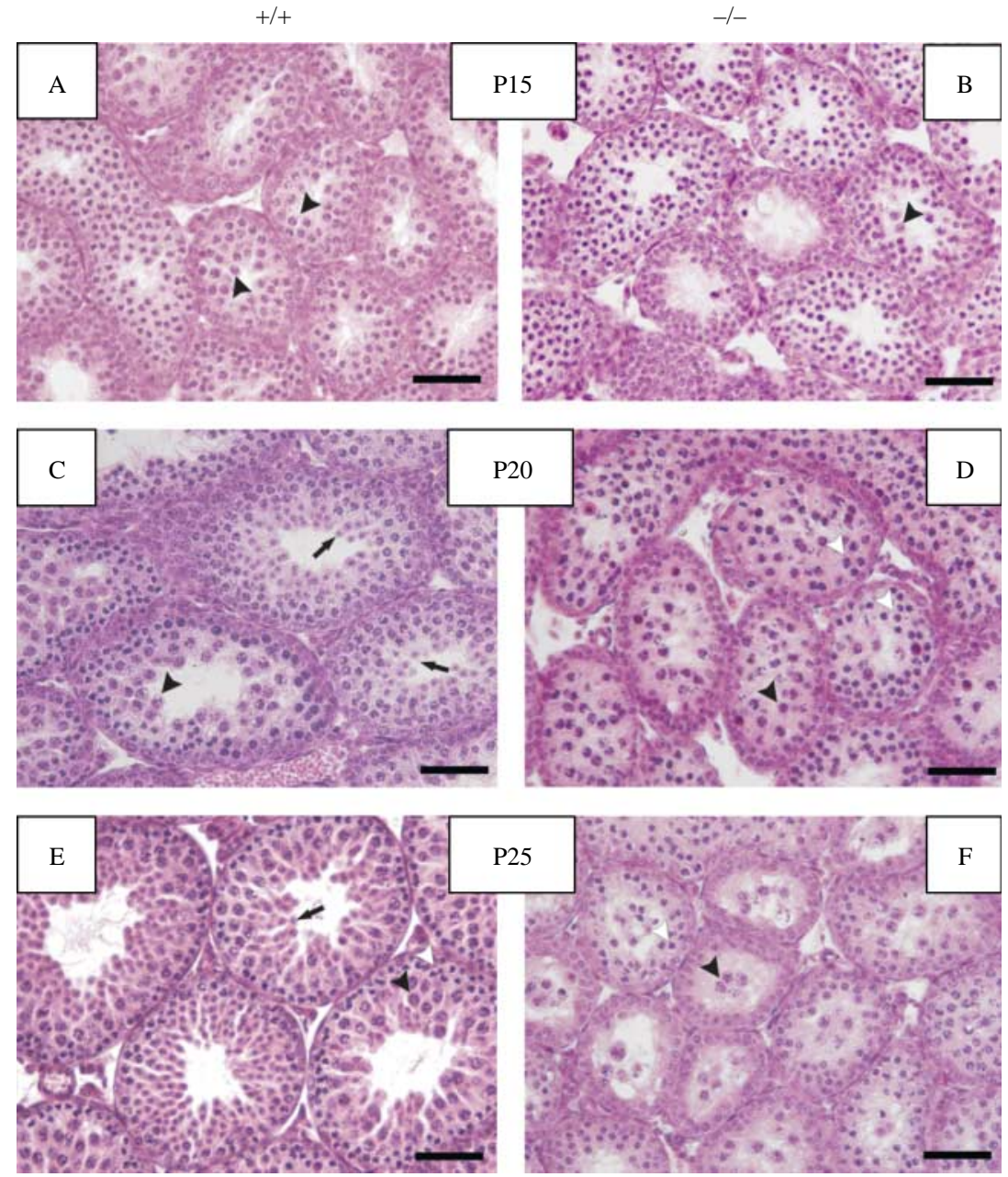

Figure 5 Delayed and disrupted first wave of spermatogenesis in $\mathrm{Hspa} 4$ mutant mice. (A-F) Testicular sections from wild-type $(+/+)$ and Hspa4-null mice $(-/-)$ at postnatal days 15 (P15), 20 (P20), and 25 (P25) were stained with $\mathrm{H} \& \mathrm{E}$. Arrowheads and arrows indicate pachytene spermatocytes and spermatids, respectively. Scale bar $=50 \mu \mathrm{m}$.

\section{Discussion}

This research describes the expression and physiological function of HSPA4 in germ cell development. Expression of HSPA4 is ubiquitously expressed in both somatic and germ cells of testis. However, the expression is highly enriched in male and female germ cells of prenatal gonads. Expression of HSPA4 in male gonocytes is gradually decreased after migration to the basal layers of seminiferous tubules and differentiation to spermatogonia. This preferential expression leads us to study the specific role of HSPA4 in germ cell development. Analyses of Hspa4-deficient mice revealed that all Hspa4-null mice on the hybrid C57BL/6J $\times 129 / \mathrm{Sv}$ genetic background were born at Mendelian ratio and were apparently normal. Although expression of HSPA4 can be detected in all tissues of wild-type mice, male infertility was the most apparent phenotype for Hspa4deficient mice of the second generation. Male infertility is histologically characterized by a decreased number of the post-meiotic germ cells and an increased number of germ cells undergoing apoptosis. Hspa4 mutants display a disruption of the first wave of spermatogenesis in juvenile testes by postnatal day 15 , when the most advanced germ cells in the testes remain at the late pachytene spermatocyte stage. The histological results were confirmed by immunohistological and RNA analyses. These results showed the presence of an equivalent number of gonocytes in neonatal Hspa4null testes and a lower percentage of mature spermatids. Expression of early meiosis-specific genes was not affected in Hspa4-deficient testes. In contrast, expression of marker genes for later stages of meiotic prophase I and for post-meiotic germ cells was downregulated in the absence of HSPA4. These results indicate that the Hspa4 deficiency impairs the development of most germ cells in late prophase I.

Numerous proteins that are required for the development of male germ cells through meiotic and postmeiotic stages are mostly translated in the pachytene spermatocyte stage (Eddy \& O'Brien 1998). Failure of molecular chaperones to direct correct folding of newly synthesized proteins might lead to accumulation of misfolded and damaged proteins in pachytene spermatocytes, which could prompt spermatocytes to undergo 

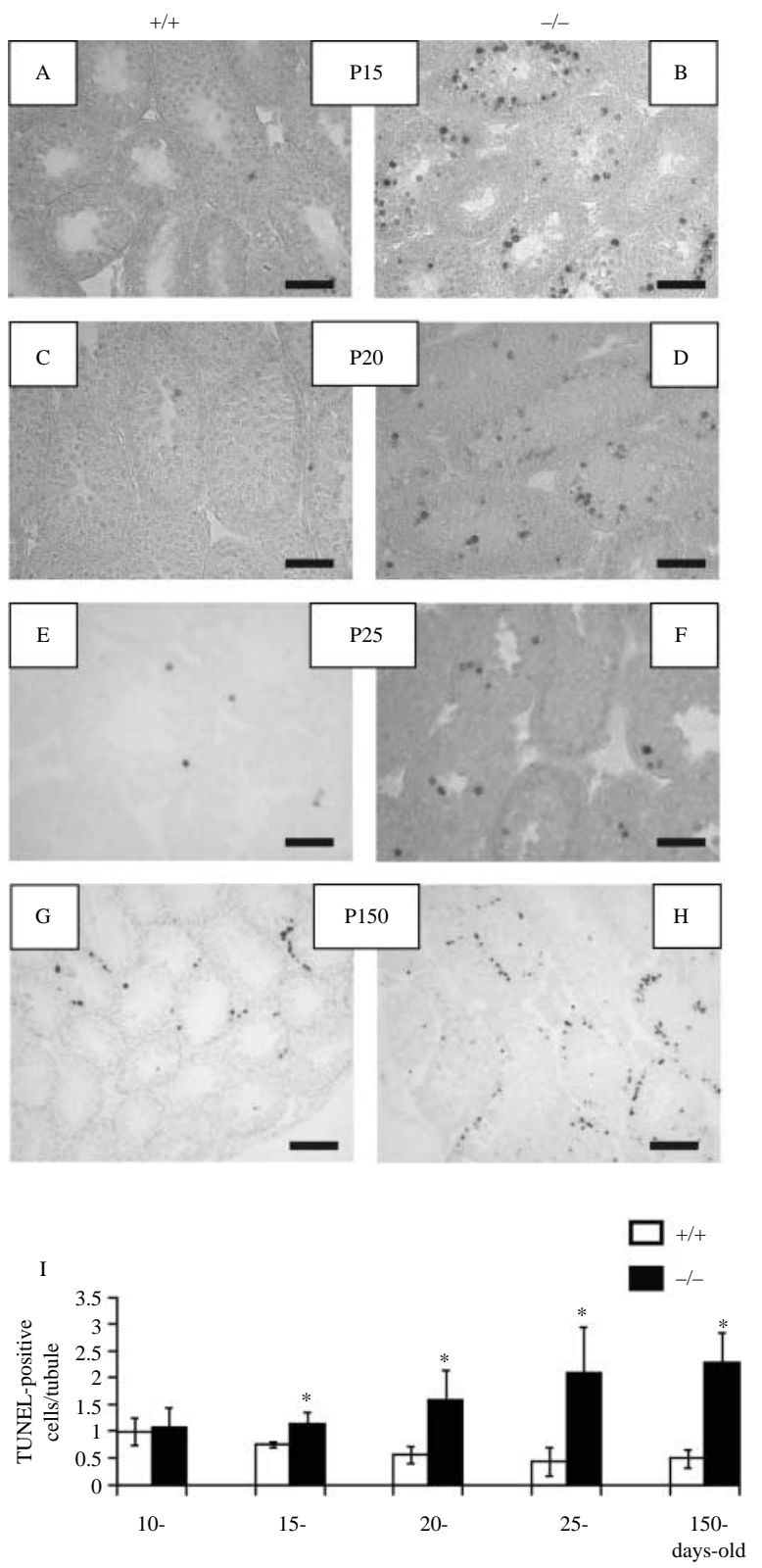

Figure 6 Enhanced apoptosis during germ cell development of Hspa4null mice. (A-H) Histological sections of $\mathrm{Hspa}^{+/+}(+/+)$and $\mathrm{Hspa4}^{-/-}$mice (-/-) at postnatal days 15 (P15), 20 (P20), 25 (P25), and 150 (P150) were subjected to TUNEL staining. TUNEL-positive cells are mainly pachytene spermatocytes as indicated by their nuclear size and their position in the seminiferous tubules. Scale bar $(\mathrm{A}-\mathrm{F})=$ $50 \mu \mathrm{m} ;(\mathrm{G}$ and $\mathrm{H})=100 \mu \mathrm{m}$. (I) For quantification of TUNEL-positive cells/seminiferous tubule, sections of testes derived from two mice per genotype per stage were microscopically analyzed. Number of the TUNEL-positive cells per tubule in each microscopic field was determined. An average of 10-20 randomly microscopic fields were scored for each genotype and developmental stage ( $n=100-150$ tubules). Then, the mean number of TUNEL-positive cells per tubule and standard deviation were calculated for the examined fields. Paired comparisons of the TUNEL-positive cells/tubule in testis among $\mathrm{Hspa}^{+/+}$and $\mathrm{Hspa}^{-/-}$mice in each stage were performed to determine the statistical significance by using Student's $t$-test. Bar graph represents mean \pm S.D. ${ }^{*} P<0.05$. apoptosis, rather carry on with meiotic division. Based on the high similarity of HSP110 family members, we expected that the molecular chaperones, which also include the NEF members of HSP110 family, would be abnormally or partially affected in $\mathrm{Hspa}^{-\prime-}$ mice. The relatively leaky phenotype of Hspa4-deficient mice led us to suggest that other members of HSP110 family can partially compensate for the loss of HSPA4 function. HSPA4L and HSPH1 are possible candidates, because both proteins are widely expressed and localized in the cytoplasm like HSPA4. Therefore, the possibility of functional compensation between these proteins would be the cause that $\mathrm{Hspa}^{-/-}$mice are viable and display normal development except for disruption of spermatogenesis. This phenotype is also not completely penetrant, because some Hspa4-deficient germ cells were able to progress through spermatogenesis. To check this possibility, we intercrossed Hspa4-deficient mice with previously described Hspa4l mutant mice to produce mice lacking both genes. We found that $\mathrm{Hspa}^{-1-}$ $H_{s p a} 4 I^{-/-}$double knockout mice developed pulmonary hypoplasia that subsequently caused neonatal death during the first day of life (unpublished data). These results suggest a redundant function for HSPA4 and HSPA4L in lung maturation.

Expression of some HSP proteins is inducible by environmental stress, but expression of others can be either constitutive or developmentally regulated (Dix et al. 1997). HSPA4 and HSPH1 are ubiquitously expressed proteins and become relatively enriched in gonocytes after colonization of gonads by primordial germ cells (Fig. 2 and our unpublished data). The enrichment of both proteins in germ stem cells suggests their significant role for male and female germ stem cells. The results showed that the gonocytes are not affected in Hspa4-deficient mice, suggesting a redundant function of both proteins in germ cell development. To our knowledge, there is no report describing abnormal spermatogenesis in Hsph1-deficient mice. In one study, Hsph1-null mice were normally fertile (Nakamura et al. 2008). We are, therefore, interested in determining the impact of deleting both HSPA4 and $\mathrm{HSPH} 1$ on germ cell development by generation and characterization of $\mathrm{H}_{\text {spa }}{ }^{-1-} \mathrm{Hsph}^{-{ }^{-}-}$double knockout mice.

Several reports, which used microarray analysis to identify preferentially expressed genes in different stem cells, revealed that the Hspa4 is highly expressed in embryonic and different tissue-specific stem cells, and its expression is downregulated in their differentiated counterparts (Ramalho-Santos et al. 2002, Bhattacharya et al. 2004). Hspa4 was one of the 216 enriched genes that were found to be expressed at high levels in embryonic, neural, and hematopoietic stem cells. Our results showing HSPA4 expression in germ stem cells further confirm the requirement of HSPA4 function for germ cell development. Although the physiological role of molecular chaperones for self-renewal of stem cells is 
A

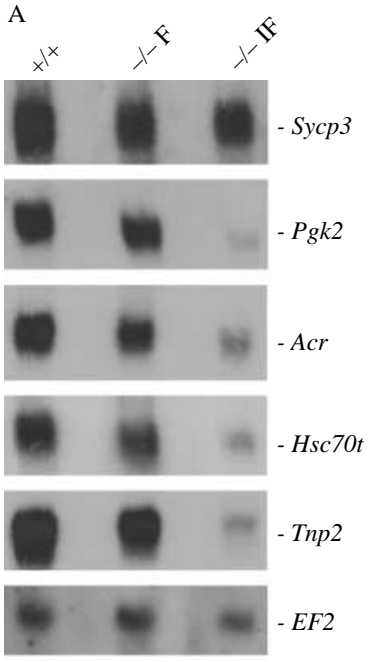

C
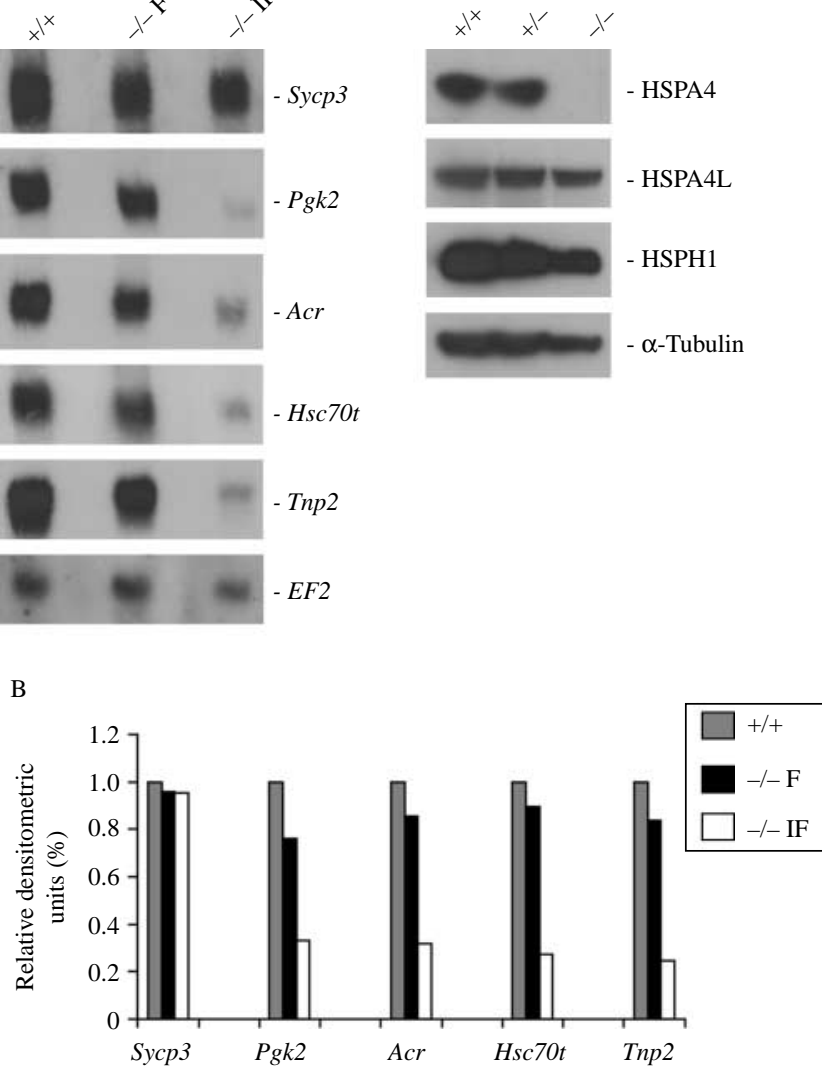

Figure 7 Expression profile of different germ cell markers and members of HSP1 10 family in $\mathrm{Hspa}^{-/-}$testes. (A) Northern blot with total RNA from testes of $\mathrm{Hspa}^{+/+}(+/+)$, fertile $(-/-\mathrm{F})$, and infertile $\mathrm{Hspa}^{-/-}$ $(-/-$ IF) mice was sequentially hybridized with cDNA probes for the indicated genes. (B) Densitometry analysis for the expression levels of different spermatogenic markers showing in Fig. 7A was determined. Expression level was expressed as relative percentage, with 1.0 given as the expression of spermatogenic marker in wild-type testis. Expression level of EF2 gene was used for normalization. (C) Expression patterns of other members of HSP110 family in testes of wild-type and Hspa4-null mice. Immunoblots were probed with the antibodies shown at the right margin.

not known, it is believed that molecular chaperones may protect stem cells from aging due to oxidative stress (Ramalho-Santos et al. 2002). Caenorhabditis elegans that have an extended life span have elevated levels of molecular chaperones and enzymes that process oxidative free radicals and appear to be resistant to environmental stresses (Finkel \& Holbrook 2000).

The partial penetrance of male infertility among Hspa4-null mice on the hybrid C57BL/6J $\times 129 / \mathrm{Sv}$ genetic background may be reflected by the segregation of genetic modifiers on the hybrid genetic background. Background-related differences in male infertility phenotype have been reported in other mutations (Pearse et al. 1997, Yu et al. 2000, Adham et al. 2001). We have observed increased incidence of male infertility among Hspa4-null mice in F2 generation, which contain a high level of inter-individual genetic variability. The decreased incidence of male infertility observed in the subsequent generation suggests that Hspa4-null males in different genetic background differ in fertility and would impose a selection bias against that genotype of infertile male. The decreased incidence of spermatogenic phenotypes in the following generations has also been described in different knockout mouse lines (Anderson et al. 2008, Burnicka-Turek et al. 2009).

The generation of Hspa4-, Hspa4l- and Hsph1deficient mice constitutes an initial step in the understanding of the physiological role of HSP110 family members in mammals.

\section{Materials and Methods Generation of HSPA4-null mice}

The PAC clone (RPCIP711P18115Q2) containing the Hspa4 locus was isolated from the 129/Sv genomic library (RZPD, Berlin, Germany). The targeting vector was designed by replacement of exon 1 containing the start codon ATG with the $P g k$-neo cassette. The $6 \mathrm{~kb} \mathrm{Spel} / \mathrm{Xhol}$ and $4.5 \mathrm{~kb} \mathrm{BamHl} /$ EcoRI genomic fragments containing the sequences of $5^{\prime}$-flanking region and intron 1 of Hspa4, respectively, were isolated from the PAC clone and inserted on either side of Pgk-neo cassette of pPNT vector (Fig. 3A). The targeting vector was linearized with Notl and used for transfection of RI ES cells. Recombined ES-cells were checked for homologous recombination by Southern blot analysis. Genomic DNA was isolated from ES cells, digested with Xbal, separated in $0.8 \%$ $(\mathrm{w} / \mathrm{v})$ agarose gels, and transferred onto nylon membrane (Amersham Pharmacia). A $0.7 \mathrm{~kb}$ fragment located at $3^{\prime}$ of targeting vector was amplified, radioactive labeled, and used as probe for the Southern blot analysis. Correctly targeted ES cell clones were injected into blastocysts derived from C57BL/6] mice and transferred into pseudo pregnant DBA/BI6 females to generate chimeric mice. The chimeric founders were mated with $\mathrm{C} 57 \mathrm{BL} / 6 \mathrm{~J}$ to generate heterozygous $\mathrm{Hspa}^{+/-}$mice, which were intercrossed to produce homozygous $\mathrm{Hspa}^{-1-}$ mice. Genotyping of mice was carried out by PCR amplification of tail DNA. A 535 bp PCR product from the wild-type allele was detected using primer F1: 5'-GATCACGGGAAGTGAGTGGT-3' and R1: 5'-GAGCGGGAG TGAGACAGTTC-3'. The targeted allele yielded a $274 \mathrm{bp}$ product with primer $\mathrm{F} 1$ : and primer PGK 5'-GGATGTGGAATGTGTGCGAGG- ${ }^{\prime}$. The thermal cycling was carried out for 35 cycles of denaturation at $94{ }^{\circ} \mathrm{C}$ for $30 \mathrm{~s}$, annealing at $55^{\circ} \mathrm{C}$ for $30 \mathrm{~s}$, and extension at $72^{\circ} \mathrm{C}$ for $30 \mathrm{~s}$. All animal experiments were reviewed and approved by the Institutional Animal Care and Use Committee of the University of Göttingen.

\section{Northern blot analysis and RT-PCR}

Total RNA was extracted using RNAeasy mini-kit (Qiagen) and resolved $(10 \mu \mathrm{g} /$ line) on an agarose gel containing $2.2 \mathrm{M}$ formaldehyde and transferred onto nylon membrane. Blots were hybridized with 358 and 596 bp cDNA fragments containing the sequences of the C-terminal coding and the 3'-untranslated regions of Hspa4, respectively. The followed 
primers were used to amplify the 358 and the 596 bp cDNA probes: $5^{\prime}$-GAAGAACTAGGGAAGCAAATCC- $3^{\prime}$ and $5^{\prime}$-TCAATGTCCATCTCAGGAAGC-3'; 5'-GTCCTGTTTAAGAGCCCAGCTA-3' and 5'-ATTTACCAT GCCTACACCCAAC- $3^{\prime}$.

RT-PCR assay was performed using $2 \mu \mathrm{g}$ total RNA and a one step RT-PCR kit (Qiagen). Primers to amplify Hspa4 and Hprt transcripts were $5^{\prime}$-GTCGGTGGTGGGCATAGAC-3'and $5^{\prime}$-TTTATGCCCGTTAATCCAGTG; 5'-GTCAAGGGCATATCCAACAACAAAC- $3^{\prime}$ and $5^{\prime}$-CCTGCTGGATTACATTAAAGCACTG-3', respectively.

Densitometry analysis was performed using the ImageJ Software (NIH, Bethesda, MD, USA); optic density for expression levels of EF2 in northern blot analysis was used for normalization.

\section{Fertility test and spermatozoa quality}

To examine the fertility of Hspa4-deficient males on a hybrid $129 / \mathrm{Sv} \times \mathrm{C} 57 \mathrm{BL} / 6$ J genetic background, mature $H_{s p a}{ }^{-/-}$ males from the second generation were intercrossed, each with two wild-type CD1 females, for at least 3 months. The number and size of litters sired by each male were determined in a 3-month mating period.

Epididymides of ten $\mathrm{Hspa}^{-/-}$and four wild-type males were collected and dissected in IVF medium (MediCult, Jyllinge, Denmark). Sperm number in cauda epididymides was determined using the Neubauer cell chamber. To determine the sperm motility, spermatozoa were incubated for $1.5 \mathrm{~h}$ at $37^{\circ} \mathrm{C}, 5 \% \mathrm{CO}_{2}$. Sperm suspension $(10 \mu \mathrm{l})$ was transferred to the incubation chamber, which was set to $37^{\circ} \mathrm{C}$. Sperm movement was quantified using the CEROS computerassisted semen analysis system (version 10, Hamilton Thorne Research, Beverly, MA, USA).

\section{Histological and immunohistochemical methods}

For histological analysis, tissues were fixed in Bouin's solution and embedded in paraffin. Sections $(6 \mu \mathrm{m})$ were stained with hematoxylin and eosin (H\&E). For immunohistochemistry, sections were preincubated for $1 \mathrm{~h}$ with $5 \%$ normal goat serum in $0.05 \%(\mathrm{v} / \mathrm{v})$ Triton-X-100-PBS; incubated overnight at $4{ }^{\circ} \mathrm{C}$ with either rabbit anti-HSPA4 (N-60; Santa Cruz Biotechnology, Santa Cruz, CA, USA) at 1:200 dilution, antiHSPA4 (N-96; Santa Cruz) at 1:200 dilution, mouse anti-germ cell nuclear protein (GCNA1) at 1:50 dilution, or anti-HSPH1 (Sigma) at 1:200 dilution; washed with PBS; and then incubated with alkaline phosphate-conjugated goat anti-rabbit antibody or anti-rate (Sigma) at 1:500 dilution for $1 \mathrm{~h}$ at room temperature. After washing with PBS, immunoreactivity was detected by incubation of the sections in a solution containing Fast Red TR/naphthol AS-MX phosphate tablets (Sigma). For PLZF and HSPA4 double immunofluorescent staining, sections of 5-day-old testes were incubated overnight at $4{ }^{\circ} \mathrm{C}$ with rabbit anti-HSPA4 and mouse anti-PLZF (D-9, Santa Cruz) antibodies. Sections were washed and then incubated with Cy3conjugated goat anti-rabbit and FITC-conjugated goat anti-mouse antibodies (Sigma) for $1 \mathrm{~h}$ at room temperature. After washing, sections were mounted with Vectashield mounting reagent (Vector, Burlingame, CA, USA) prior to fluorescence microscopy (Olympus, Hamburg, Germany).

TUNEL-positive cells were detected using an ApopTaq peroxidase in situ apoptosis kit (Obiogene, Heidelberg, Germany) according to the manufacturer's instruction.

\section{Western blot analysis}

Tissues were sonicated in RIPA buffer (Santa Cruz). Protein lysates were cleared by centrifugation at $16000 \mathrm{~g}$ at $4{ }^{\circ} \mathrm{C}$ for $20 \mathrm{~min}$, and protein concentration was measured by the Bradford assay (Bio-Rad). Total cell lysate $(20 \mu \mathrm{g})$ was then resolved in $15 \%(\mathrm{w} / \mathrm{v})$ SDS-PAGE gel and electroblotted onto nitrocellulose membrane. After blocking with 5\% (w/v) skimmed milk in PBS, blots were incubated with either the primary antibodies rabbit anti-HSPA4 (1:500, Santa Cruz), rabbit anti-HSPA4L (1:500, Santa Cruz), rabbit anti-HSPH1 (1:1000, Sigma), or monoclonal anti- $\alpha$-tubulin (1:10000, Sigma) with skimmed milk in PBS overnight at $4{ }^{\circ} \mathrm{C}$. After a washing step, blots were incubated with HRP-conjugated anti-rabbit or antimouse IgG (1:2000, Sigma). The detection of immunoreactivity was performed using enhanced chemiluminescence (Pierce Chemical, Rockford, IL, USA).

\section{Statistical analysis}

Paired comparisons of the different sperm parameters and the number of apoptotic cells/tubule in testis among $\mathrm{Hspa}^{-/-}$ and $\mathrm{Hspa}^{+/+}$mice were performed for statistical significance by calculating means \pm s.D. and Student's $t$-test.

\section{Supplementary data}

This is linked to the online version of the paper at http://dx.doi. org/10.1530/REP-11-0023.

\section{Declaration of interest}

The authors declare that there is no conflict of interest that could be perceived as prejudicing the impartiality of the research reported.

\section{Funding}

B A Mohamed is supported by the DAAD through grant A/07/80490.

\section{Acknowledgements}

We thank M Schindler, S Wolf and U Fünfschilling for their help in the generation and breeding of knockout mice; A Nagy (Mount Sinai Hospital, Toronto, Canada) for providing RI ES cells; and G C Enders (Kansas University, Medical Center, Kansas City, USA) for providing the GCNA1 antibody. Parts of this research are components of the PhD thesis of T Held: 'Zur Strukturellen und Funktionellen Analyse der Murinen Gene der HSP110 Familie'. 


\section{References}

Adham IM, Nayernia K, Burkhardt-Göttges E, Topaloglu O, Dixkens C, Holstein AF \& Engel W 2001 Teratozoospermia in mice lacking the transition protein 2 (Tnp2). Molecular Human Reproduction 7 513-520. (doi:10.1093/molehr/7.6.513)

Anderson EL, Baltus AE, Roepers-Gajadien HL, Hassold TJ, de Rooij DG, van Pelt AM \& Page DC 2008 Stra8 and its inducer, retinoic acid, regulate meiotic initiation in both spermatogenesis and oogenesis in mice. PNAS 105 14976-14980. (doi:10.1073/pnas.0807297105)

Bhattacharya B, Miura T, Brandenberger R, Mejido J, Luo Y, Yang AX, Joshi BH, Ginis I, Thies RS, Amit M et al. 2004 Gene expression in human embryonic stem cell lines: unique molecular signature. Blood 103 2956-2964. (doi:10.1182/blood-2003-09-3314)

Burnicka-Turek O, Shirneshan K, Paprotta I, Grzmil P, Meinhardt A, Engel W \& Adham IM 2009 Inactivation of insulin-like factor 6 disrupts the progression of spermatogenesis at late meiotic prophase. Endocrinology 150 4348-4357. (doi:10.1210/en.2009-0201)

Chubb C 1992 Oligotriche and quaking gene mutations. Phenotypic effects on mouse spermatogenesis and testicular steroidogenesis. Journal of Andrology 13 312-317.

Dix DJ, Allen JW, Collins BW, Poorman-Allen P, Mori C, Blizard DR, Brown PR, Goulding EH, Strong BD \& Eddy EM 1997 HSP70-2 is required for desynapsis of synaptonemal complexes during meiotic prophase in juvenile and adult mouse spermatocytes. Development 124 4595-4603.

Dragovic Z, Broadley SA, Shomura Y, Bracher A \& Hartl FU 2006 Molecular chaperones of the Hsp110 family act as nucleotide exchange factors of Hsp70s. EMBO Journal 25 2519-2528. (doi:10.1038/sj.emboj. 7601138)

Dym M \& Fawcett DW 1971 Further observations on the numbers of spermatogonia, spermatocytes, and spermatids connected by intercellular bridges in the mammalian testis. Biology of Reproduction 4 195-215.

Eddy EM 1999 Role of heat shock protein HSP70-2 in spermatogenesis. Reviews of Reproduction 4 23-30. (doi:10.1530/ror.0.0040023)

Eddy EM \& O'Brien DA 1998 Gene expression during mammalian meiosis. Current Topics in Developmental Biology 37 141-200.

Finkel T \& Holbrook NJ 2000 Oxidants, oxidative stress and the biology of ageing. Nature 408 239-247. (doi:10.1038/35041687)

Goto M, Koji T, Mizuno K, Tamaru M, Koikeda S, Nakane PK, Mori N, Masamune Y \& Nakanishi Y 1990 Transcription switch of two phosphoglycerate kinase genes during spermatogenesis as determined with mouse testis sections in situ. Experimental Cell Research 183 273-278. (doi:10.1016/0014-4827(90)90306-U)

Gotoh K, Nonoguchi K, Higashitsuji H, Kaneko Y, Sakurai T, Sumitomo Y, Itoh K, Subjeck JR \& Fujita J 2004 Apg-2 has a chaperone-like activity similar to Hsp110 and is overexpressed in hepatocellular carcinomas. FEBS Letters 560 19-24. (doi:10.1016/S0014-5793(04) 00034-1)

Guan K, Nayernia K, Maier LS, Wagner S, Dressel R, Lee JH, Nolte J, Wolf F, Li M, Engel W et al. 2006 Pluripotency of spermatogonial stem cells from adult mouse testis. Nature 440 1199-1203. (doi:10.1038/nature04697)

Hartl FU 1996 Molecular chaperones in cellular protein folding. Nature 381 571-579. (doi:10.1038/381571a0)

Held T, Paprotta I, Khulan J, Hemmerlein B, Binder L, Wolf S, Schubert S, Meinhardt A, Engel W \& Adham IM 2006 Hspa4l-deficient mice display increased incidence of male infertility and hydronephrosis development. Molecular and Cellular Endocrinology 26 8099-8108. (doi:10.1128/ MCB.01332-06)

Kaneko Y, Kimura T, Kishishita M, Noda Y \& Fujita J 1997 Cloning of apg-2 encoding a novel member of heat shock protein 110 family. Gene $\mathbf{1 8 9}$ 19-24. (doi:10.1016/S0378-1119(96)00807-4)

Kashiwabara S, Arai Y, Kodaira K \& Baba T 1990 Acrosin biosynthesis in meiotic and postmeiotic spermatogenic cells. Biochemical and Biophysical Research Communications 173 240-245. (doi:10.1016/ S0006-291X(05)81047-2)

Kleene KC \& Flynn JF 1987 Characterization of a CDNA clone encoding a basic protein, TP2, involved in chromatin condensation during spermatogenesis in the mouse. Journal of Biological Chemistry 262 17272-17277.
Kremling H, Keime S, Wilhelm K, Adham IM, Hameister H \& Engel W 1991 Mouse proacrosin gene: nucleotide sequence, diploid expression, and chromosomal localization. Genomics 11 828-834. (doi:10.1016/08887543(91)90005-Y)

Lammers JH, Offenberg HH, van Aalderen M, Vink AC, Dietrich AJ \& Heyting C 1994 The gene encoding a major component of the lateral elements of synaptonemal complexes of the rat is related to X-linked lymphocyte-regulated genes. Molecular and Cellular Endocrinology 14 1137-1146.

Li C, Liu D, Yuan Y, Huang S, Shi M, Tao K \& Feng W 2010 Overexpression of Apg-2 increases cell proliferation and protects from oxidative damage in BaF3-BCR/ABL cells. International Journal of Oncology 36 899-904. (doi:10.3892/ijo_00000568)

Liu Q \& Hendrickson WA 2007 Insights into Hsp70 chaperone activity from a crystal structure of the yeast Hsp110 Sse1. Cell 131 106-120. (doi:10. 1016/j.cell.2007.08.039)

Lyon MF, Searle AG 1989 Genetic Variants and Strains of the Laboratory Mouse, 2nd edn. Oxford: Oxford University Press.

Mayer MP \& Bukau B 2005 Hsp70 chaperones: cellular functions and molecular mechanism. Cellular and Molecular Life Sciences 62 670-684. (doi:10.1007/s00018-004-4464-6)

McLean DJ, Friel PJ, Johnston DS \& Griswold MD 2003 Characterization of spermatogonial stem cell maturation and differentiation in neonatal mice. Biology of Reproduction 69 2085-2091. (doi:10.1095/biolreprod. 103.017020)

Nagano R, Tabata S, Nakanishi Y, Ohsako S, Kurohmaru M \& Hayashi Y 2000 Reproliferation and relocation of mouse male germ cells (gonocytes) during prespermatogenesis. Anatomical Record $\mathbf{2 5 8}$ 210-220. (doi:10.1002/(SICl)1097-0185(20000201)258:2<210::AIDAR10>3.0.CO;2-X)

Nakamura J, Fujimoto M, Yasuda K, Takeda K, Akira S, Hatayama T, Takagi Y, Nozaki K, Hosokawa N \& Nagata K 2008 Targeted disruption of Hsp110/105 gene protects against ischemic stress. Stroke 39 2853-2859. (doi:10.1161/STROKEAHA.107.506188)

Nonoguchi K, Itoh K, Xue JH, Tokuchi $\mathrm{H}$, Nishiyama $\mathrm{H}$, Kaneko $\mathrm{Y}$, Tatsumi K, Okuno H, Tomiwa K \& Fujita J 1999 Cloning of human cDNAs for Apg-1 and Apg-2, members of the Hsp110 family, and chromosomal assignment of their genes. Gene 37 21-28. (doi:10.1016/ S0378-1119(99)00325-X)

Pearse RV, Drolet DW, Kalla KA, Hooshmand F, Bermingham JR Jr \& Rosenfeld MG 1997 Reduced fertility in mice deficient for the POU protein sperm-1. PNAS 94 7555-7560. (doi:10.1073/pnas.94.14.7555)

Polier S, Dragovic Z, Hartl FU \& Bracher A 2008 Structural basis for the cooperation of Hsp70 and Hsp110 chaperones in protein folding. Cell 133 1068-1079. (doi:10.1016/j.cell.2008.05.022)

Ramalho-Santos M, Yoon S, Matsuzaki Y, Mulligan RC \& Melton DA 2002 "Stemness": transcriptional profiling of embryonic and adult stem cells. Science 298 597-600. (doi:10.1126/science.1072530)

Rassoulzadegan M, Paquis-Flucklinger V, Bertino B, Sage J, Jasin M, Miyagawa K, van Heyningen V, Besmer P \& Cuzin F 1993 Transmeiotic differentiation of male germ cells in culture. Cell 75 997-1006. (doi:10. 1016/0092-8674(93)90543-Y)

Raviol H, Sadlish H, Rodriguez F, Mayer MP \& Bukau B 2006 Chaperone network in the yeast cytosol: Hsp110 is revealed as an Hsp70 nucleotide exchange factor. EMBO Journal 25 2510-2518. (doi:10.1038/sj.emboj. 7601139)

Schuermann JP, Jiang J, Cuellar J, Llorca O, Wang L, Gimenez LE, Jin S, Taylor AB, Demeler B, Morano KA et al. 2008 Structure of the Hsp110:Hsc70 nucleotide exchange machine. Molecular Cell 31 232-243. (doi:10.1016/j.molcel.2008.05.006)

Steel GJ, Fullerton DM, Tyson JR \& Stirling CJ 2004 Coordinated activation of Hsp70 chaperones. Science 303 98-101. (doi:10.1126/science. 1092287)

Terada K, Yomogida K, Imai T, Kiyonari H, Takeda N, Kadomatsu T, Yano M, Aizawa S \& Mori M 2005 A type I Dnal homolog, DjA1, regulates androgen receptor signaling and spermatogenesis. EMBO Journal 24 611-622. (doi:10.1038/sj.emboj.7600549)

Tsunekawa N, Matsumoto M, Tone S, Nishida T \& Fujimoto H 1999 The Hsp70 homolog gene, Hsc70t, is expressed under translational control during mouse spermiogenesis. Molecular Reproduction and Development 52 383-391. (doi:10.1002/(SICI)1098-2795(199904)52:4 $<383:$ :AID-MRD7>3.0.CO;2-Z) 
Vergouwen RP, Jacobs SG, Huiskamp R, Davids JA \& de Rooij DG 1991 Proliferative activity of gonocytes. Sertoli cells and interstitial cells during testicular development in mice. Journal of Reproduction and Fertility $\mathbf{9 3}$ 233-243. (doi:10.1530/jrf.0.0930233)

Vos MJ, Hageman J, Carra S \& Kampinga HH 2008 Structural and functional diversities between members of the human HSPB, HSPH, HSPA, and DNAJ chaperone families. Biochemistry 47 7001-7011. (doi:10.1021/bi800639z)

Yu YE, Zhang Y, Unni E, Shirley CR, Deng JM, Russell LD, Weil MM, Behringer RR \& Meistrich ML 2000 Abnormal spermatogenesis and reduced fertility in transition nuclear protein 1-deficient mice. PNAS 79 4683-4688. (doi:10.1073/pnas.97.9.4683)
Zimmermann S, Steding G, Emmen JM, Brinkmann AO, Nayernia K, Holstein AF, Engel W \& Adham IM 1999 Targeted disruption of the Insl3 gene causes bilateral cryptorchidism. Molecular Endocrinology 13 681-691. (doi:10.1210/me.13.5.681)

Received 26 January 2011

First decision 21 February 2011

Accepted 12 April 2011 